\title{
RESEARCH
}

Open Access

\section{Resveratrol ameliorates prenatal progestin exposure-induced autism-like behavior through ER $\beta$ activation}

Weiguo Xie ${ }^{1+}$, Xiaohu Ge ${ }^{2+}$, Ling $\mathrm{Li}^{3+}$, Athena Yao ${ }^{1}$, Xiaoyan Wang ${ }^{2}$, Min $\mathrm{Li}^{1}$, Xiang Gong ${ }^{1}$, Zhigang Chu' ${ }^{1}$ Zhe $\mathrm{Lu}^{3}$, Xiaodong Huang ${ }^{1}$, Yun Jiao ${ }^{3}$, Yifei Wang ${ }^{2}$, Meifang Xiao ${ }^{3}$, Haijia Chen ${ }^{2^{*}}$, Wei Xiang ${ }^{3^{*}}$ and Paul Yao ${ }^{1,3^{*}}$ (D)

\begin{abstract}
Background: Recent literatures indicate that maternal hormone exposure is a risk factor for autism spectrum disorder (ASD). We hypothesize that prenatal progestin exposure may counteract the neuroprotective effect of estrogen and contribute to ASD development, and we aim to develop a method to ameliorate prenatal progestin exposure-induced autism-like behavior.

Methods: Experiment 1: Prenatal progestin exposure-induced offspring are treated with resveratrol (RSV) through either prenatal or postnatal exposure and then used for autism-like behavior testing and other biomedical analyses. Experiment 2: Prenatal norethindrone (NET) exposure-induced offspring are treated with ERß knockdown lentivirus together with RSV for further testing. Experiment 3: Pregnant dams are treated with prenatal NET exposure together with RSV, and the offspring are used for further testing.

Results: Eight kinds of clinically relevant progestins were used for prenatal exposure in pregnant dams, and the offspring showed decreased ERß expression in the amygdala with autism-like behavior. Oral administration of either postnatal or prenatal RSV treatment significantly reversed this effect with ER $\beta$ activation and ameliorated autism-like behavior. Further investigation showed that RSV activates ER $\beta$ and its target genes by demethylation of DNA and histone on the ERß promoter, and then minimizes progestin-induced oxidative stress as well as the dysfunction of mitochondria and lipid metabolism in the brain, subsequently ameliorating autism-like behavior.

Conclusions: We conclude that resveratrol ameliorates prenatal progestin exposure-induced autism-like behavior through ER $\beta$ activation. Our data suggest that prenatal progestin exposure is a strong risk factor for autism-like behavior. Many potential clinical progestin applications, including oral contraceptive pills, preterm birth drugs, and progestin-contaminated drinking water or seafood, may be risk factors for ASD. In addition, RSV may be a good candidate for clinically rescuing or preventing ASD symptoms in humans, while high doses of resveratrol used in the animals may be a potential limitation for human application.
\end{abstract}

Keywords: Autism spectrum disorder, Estrogen receptor $\beta$, Lipid metabolism, Mitochondria, Oxidative stress, Progestin, Resveratrol

\footnotetext{
*Correspondence: chenhaijia@saliai.com; xiangwei8@163.com;

vasilis112@yahoo.com

${ }^{\dagger}$ Weiguo Xie, Xiaohu Ge and Ling Li contributed equally to this work.

${ }^{2}$ SALIAI Stem Cell Institute of Guangdong, Guangzhou SALIAI Stem Cell

Science and Technology Co. LTD, Guangzhou 510055, People's Republic of

China

${ }^{3}$ Department of Pediatrics, Hainan Maternal and Child Health Hospital,

Haikou 570206, People's Republic of China

${ }^{1}$ Institute of Rehabilitation Center, Tongren Hospital of Wuhan University,

Wuhan 430060, People's Republic of China
}

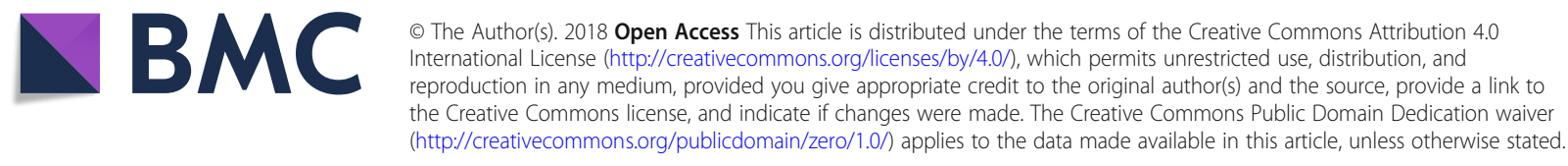




\section{Background}

Autism spectrum disorder (ASD) is a neurological and developmental disorder that is characterized by deficits in social communication and interaction with restricted and repetitive patterns of behavior [1]. The prevalence of ASD is estimated to be 1:68 and biased towards males with a male-to-female ratio of at least 4:1 [2, 3]. Many risk factors contribute to ASD development, including genetics, sex, and environmental factors $[4,5]$, while the detailed mechanisms of ASD remain unclear [6].

Recent literatures have shown that dysregulation of estrogen receptor $\beta$ (ER $\beta)$ is associated with ASD [7-10]. ER $\beta$ regulates the basal expression of superoxide dismutase (SOD2), which regulates oxidative stress [11], and estrogen-related receptor $\alpha(E R R \alpha)$ [12], which regulates mitochondrial function and lipid metabolism [13, 14]. ER $\beta$ suppression results in oxidative stress and dysfunction of mitochondrial and lipid metabolism, subsequently triggering brain damage and autism-like behavior $[9,15]$. This indicates that hormone-mediated ER $\beta$ suppression may contribute to ASD development.

It has been reported that maternal hormonal exposure is a significant risk factor for ASD $[8,16]$ as steroidogenic activity is elevated in some ASD patients [17] and cholesterol metabolism and various steroid abnormalities are involved in ASD development [18]. In addition, natural progesterone and synthetic progestin regulate neurogenic responses [19] and impair cognitive flexibility during development [20] as well as downregulate ER $\beta$ expression $[9,21]$. We hypothesize that clinically relevant progestin may counteract estrogen-mediated neuroprotective effects via downregulation of $E R \beta$, and contribute to ASD development [22, 23].

Resveratrol (RSV) is a natural polyphenolic compound that is present at high levels in red grapes, nuts, pomegranates, and Polygonum cuspidatum [24]. Resveratrol (RSV) has much therapeutic potential with its antioxidant, antitumorigenic, and cardioprotective as well as neuroprotective effects [24-28]. All of these biological activities may have potential benefits and points of interest in autism therapeutics, although very little research has been reported on its potential effect on ASD treatment [15, 29, 30].

In this study, different kinds of clinically relevant progestins were used for prenatal exposure in pregnant dams, and the offspring showed decreased ER $\beta$ expression in the brain with autism-like behavior. Oral administration of resveratrol (RSV) by either postnatal or prenatal treatment completely reversed this effect with ER $\beta$ activation and ameliorated autism-like behavior. Further investigation showed that RSV-mediated ER $\beta$ activation is due to RSV-mediated demethylation of DNA and histone on the ER $\beta$ promoter. This is the first time we have discovered the potential mechanism of ASD development due to prenatal progestin exposure-induced ER $\beta$ suppression, as well as the potential rescuing and preventive effect of RSV on autism-like behavior through ER $\beta$ activation, which may potentially be applicable in clinical treatment of ASD patients.

\section{Methods}

A detailed description can be found in Additional file 1.

\section{Materials}

17ß-estradiol (E2, \#E2758); progesterone (P4, \#P0130); levonorgestrel (LNG, \#1362602); medroxyprogesterone acetate (MPA, \#1378001); nestorone (NES, \# SML0550); norethindrone (NET, \#1469005); norethindrone acetate (NETA, \#1470004); norgestimate (NGM, \# 1471914); hydroxyprogesterone caproate (OHPC, \#1329006), and resveratrol (RSV, \#R5010) were obtained from Sigma. Norethynodrel (NEN, \#E4600-000) was obtained from Steraloids.

\section{In vivo rat experiments}

The animal protocol conformed to the US NIH guidelines (Guide for the Care and Use of Laboratory Animals, No. 85-23, revised 1996) and was reviewed and approved by the Institutional Animal Care and Use Committee from Wuhan University [9].

\section{Protocol 1 for postnatal treatment of resveratrol}

Three-month-old female Sprague Dawley rats were caged with proven males, and the verified pregnant dams were randomly assigned to either $20 \mathrm{mg}$ of progestin (such as norethindrone, NET) or VEH (vehicle group that received the same volume of vehicle). Drugs were suspended in 5\% ethanol in organic sesame oil and $0.1 \mathrm{ml}$ was given daily through subcutaneous injection at the nape starting from day 1 until pup delivery for $\sim 21$ days. The male and female offspring were separated from the dams on day 21, and then at 5 weeks old, the offspring from either VEH or progestin prenatal treatment were randomly divided into two groups, a resveratrol (RSV) group and a control (CTL) group. Rats in the RSV group were orally administered (by gavage) $20 \mathrm{mg} / \mathrm{kg}$ of RVS suspended in $10 \mathrm{~g} / \mathrm{l}$ carboxymethylcellulose every day for 4 weeks (28 days). Those in the CTL group were administered $10 \mathrm{ml} / \mathrm{kg}$ of $10 \mathrm{~g} / \mathrm{l} \mathrm{car-}$ boxymethylcellulose during the same period. At 10 weeks old, treated offspring were used for autism-like behavior testing or were sacrificed for further experiments and biomedical analysis [9]; see schematic details in Fig. 1a.

\section{Protocol 2 for postnatal treatment of resveratrol with infusion of shER $\beta$ lentivirus}

The male offspring (8 weeks old) from the VEH and NET group in Protocol 1 were anesthetized with a mixture of ketamine $(90 \mathrm{mg} / \mathrm{kg})$ and xylazine $(2.7 \mathrm{mg} / \mathrm{kg})$ and 


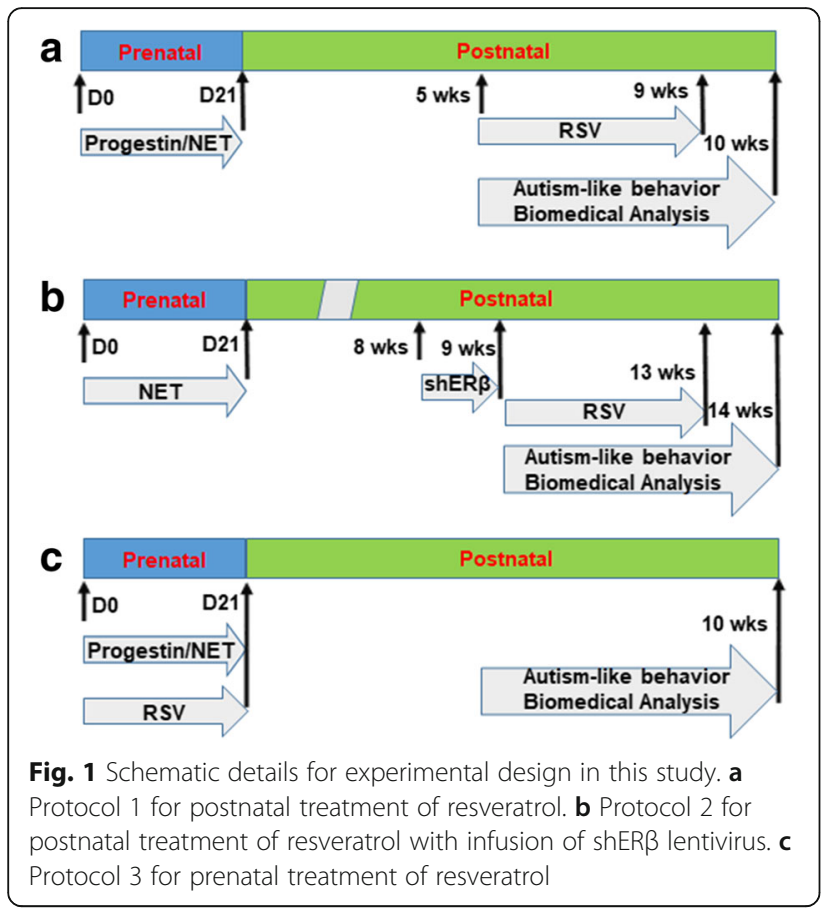

implanted with a guide cannula targeting the amygdala (26 gauge; Plastics One). The following coordinates were chosen for the amygdala: $-2.0 \mathrm{~mm}$ posterior to the bregma, $\pm 4.2 \mathrm{~mm}$ from the midline, and $-7.2 \mathrm{~mm}$ from the skull surface on which it was based. Cannula was attached to the skull with dental acrylic and jeweler's screws and closed with an obturator [31]. An osmotic minipump (Alzet model 2002; flow rate $0.5 \mu \mathrm{l} / \mathrm{h}$; Cupertino, CA) connected to a 26-gauge internal cannula that extended $1 \mathrm{~mm}$ below the guide was implanted and used to deliver either ER $\beta$ knockdown (shER $\beta$ ), or empty (EMP) lentivirus. Vehicle consisting of artificial cerebrospinal fluid (aCSF; $140 \mathrm{mM} \mathrm{NaCl}, 3 \mathrm{mM} \mathrm{KCl}, 1.2 \mathrm{mM} \mathrm{Na}_{2} \mathrm{HPO}_{4}$, $1 \mathrm{mM} \mathrm{MgCl}_{2}, 0.27 \mathrm{mM} \mathrm{NaH}_{2} \mathrm{PO}_{4}, 1.2 \mathrm{mM} \mathrm{CaCl}_{2}$, and 7.2 mM dextrose, $\mathrm{pH}$ 7.4) was used for the infusion of the lentivirus. Infusion (flow rate $0.5 \mu \mathrm{l} / \mathrm{h}$ ) began immediately after placement of the minipump. $0.5 \mu$ l of total $2 \times$ $10^{3} \mathrm{cfu}$ of lentivirus was infused for $1 \mathrm{~h}$ [9]. The experimental rats were separated into four groups (12 per group) at 9 weeks old. Group 1: VEH offspring with empty control lentivirus infusion plus oral administration of carboxymethylcellulose control treatment for 4 weeks (VEH/ EMP/CTL); Group 2: NET offspring with empty control lentivirus infusion plus oral administration of carboxymethylcellulose control treatment for 4 weeks (NET/ EMP/CTL); Group 3: NET offspring with empty control lentivirus infusion plus oral administration of resveratrol (RSV) treatment for 4 weeks (NET/EMP/RSV); Group 4: NET offspring with ER $\beta$ knockdown lentivirus infusion plus oral administration (by gavage) of RSV treatment for 4 weeks (VEH/shER $\beta / R S V)$. At 14 weeks old, the offspring were used for behavior testing followed by biomedical analysis [9]; see schematic details in Fig. 1 b.

\section{Protocol 3 for prenatal treatment of resveratrol}

Three-month-old verified pregnant dams were randomly assigned to the following four groups: Group 1: The rats received VEH (5\% ethanol in organic sesame oil and $0.1 \mathrm{ml}$ were given daily through subcutaneous injection at the nape) plus control (CTL) group with oral administration of $10 \mathrm{ml} / \mathrm{kg}$ of $10 \mathrm{~g} / \mathrm{l}$ carboxymethylcellulose (VEH/PreCTL); Group 2: Rats received $20 \mu \mathrm{g}$ of progestin (such as norethindrone, NET) with $5 \%$ ethanol in organic sesame oil plus) plus CTL group (NET/PreCTL); Group 3: The rats received VEH treatment plus resveratrol (RSV) group with oral administration (by gavage) of $20 \mathrm{mg} / \mathrm{kg}$ of resveratrol suspended in $10 \mathrm{~g} / \mathrm{l}$ carboxymethylcellulose (VEH/PreRSV); Group 4: The rats received progestin (such as NET) group plus RSV group (NET/PreRSV). The rats received the above treatment starting from day 1 until pup delivery for $\sim 21$ days. Both male and female offspring were raised until 10 weeks old to be tested for autism-like behavior testing and other biomedical analysis [9], see schematic details in Fig. 1c.

\section{Animal behavior test}

The animal behavior test of offspring was carried out at 10 weeks of age. Female offspring were tested in the diestrus phase, which was confirmed by vaginal smears. Autism-like behavior was evaluated using the marble burying test (MBT) and social interaction (SI) test.

\section{Marble burying test (MBT)}

In brief, each rat is placed in a clean cage $(35 \times 23 \times$ $19 \mathrm{~cm}^{3}$ ) filled with wood chip bedding to a depth of $5 \mathrm{~cm}$ containing 20 colored glass marbles $(1 \mathrm{~cm}$ diameter) placed in a $5 \times 4$ arrangement. The number of marbles buried ( $>50 \%$ covered by bedding material) in 30 min was hand-scored by the experimenter [9, 32, 33].

\section{Social interaction (SI) test}

In short, the subjects (Test and Stranger) were separately habituated to the arena for 5 min before the test. During each test, the rats were placed into the apparatus over a period of $20 \mathrm{~min}$ and the time spent following, mounting, grooming, and sniffing any body parts of the other rat was taken as an indicator of social engagement, and the social interaction time was calculated and analyzed using EthoVision XT animal tracking software (Noldus, USA) [34]. The animal used as the "Stranger" was used only once and was a Sprague Dawley rat of the same gender, weight, and age, with no previous contact with the test rats $[9,32,33]$. 


\section{Methods}

The amygdala neurons were isolated for in vitro primary cell culture analysis $[9,35]$. The DNA methylation on the rat ER $\beta$ promoter was evaluated by a real-time PCR-based methylation-specific PCR (MSP) analysis as described previously with some modifications [9, 36-38]. The lentivirus for rat ER $\beta$ shRNA and empty control (EMP) were prepared previously in our lab [9]. The mRNA was measured by real-time quantitative PCR using primers provided in Additional file 1: Table S1, and the protein was measured by western blotting [9]. The SIRT1 activity assay was evaluated in nuclear extract using a SIRT1 Fluorometric Drug Discovery Kit (Cat \#: BML-AK555, Enzo Life Sciences) [39]. Oxidative stress was evaluated by in vivo superoxide anion $\left(\mathrm{O}_{2}^{-}\right)$release [40] and 3-nitrotyrosine formation. DNA damage was evaluated by $8-\mathrm{OHdG}$ and $\gamma \mathrm{H} 2 \mathrm{AX}$ formation [9]. Mitochondrial function was evaluated by mitochondrial DNA copies [9] and intracellular ATP level [40]. The histone methylation was evaluated by chromatin immunoprecipitation (ChIP) analysis [9]. Fatty acid metabolism was evaluated by in vitro lipid transport assay [41] and fatty acid oxidation assay [42, 43]. Statistical analysis was conducted using SPSS 22 software, and a $P$ value of $<0.05$ was considered significant, and the data was given as mean \pm SEM [9].

\section{Results}

Postnatal resveratrol treatment reverses prenatal progestin exposure-induced ER $\beta$ suppression and autism-like behavior We first investigated the potential effect of prenatal progestin exposure on ER $\beta$ expression in the amygdala and autism-like behavior in 10-week-old male offspring, and then evaluated whether postnatal resveratrol treatment could reverse this effect. In Table 1 (left panel of first row), several steroids, $17 \beta$-estradiol (E2), progesterone (P4), and eight different kinds of clinically relevant progestins, including levonorgestrel (LNG), medroxyprogesterone acetate (MPA), nestorone (NES), norethindrone (NET), norethindrone acetate (NETA), norethynodrel (NEN), norgestimate (NGM), and hydroxyprogesterone caproate (OHPC), were used for prenatal exposure to different 3-month-old pregnant dams for 21 days $(n=8)$. The 5-week-old male offspring were then treated by either control (CTL) or resveratrol (RSV) for 4 weeks, and the ER $\beta$ mRNA in the amygdala was evaluated by real-time PCR and the autism-like behavior was evaluated by social interaction time. Our results showed that E2 had no effect, while P4 slightly decreased ER $\beta$ expression but had no significant effect on social interaction time, and almost all the clinically relevant progestins significantly decreased ER $\beta$ expression (except the NGM), and decreased social interaction time (except the NEN) compared to the vehicle group. Furthermore, resveratrol treatment almost completely reversed the suppression effect on ER $\beta$ expression and social interaction time (partly for the NES and NGM). Our results indicate that postnatal resveratrol treatment reverses prenatal progestin exposure-induced ER $\beta$ suppression and autism-like behavior.

\section{Prenatal resveratrol treatment prevents prenatal progestin} exposure-induced ER $\beta$ suppression and autism-like behavior We then evaluated the potential effect of prenatal resveratrol treatment on prenatal progestin exposure-induced ER $\beta$ suppression and autism-like behavior. In Table 1

Table 1 Resveratrol reverses and prevents prenatal progestin exposure-induced ERß suppression and autism-like behavior

\begin{tabular}{|c|c|c|c|c|c|c|c|c|}
\hline \multirow{3}{*}{$\begin{array}{l}\text { Rats } \\
\text { Prenatal } \\
\text { progestin } \\
\text { exposure }\end{array}$} & \multicolumn{4}{|c|}{ Postnatal treatment of RSV } & \multicolumn{4}{|c|}{ Prenatal treatment of RSV } \\
\hline & \multicolumn{2}{|c|}{ ERß mRNA level (\%) } & \multicolumn{2}{|c|}{ Social interaction time (seconds) } & \multicolumn{2}{|c|}{ ERß mRNA level (\%) } & \multicolumn{2}{|c|}{ Social interaction time (seconds) } \\
\hline & Control & RSV & Control & RSV & Control & RSV & Control & RSV \\
\hline Vehicle & $100 \pm 9$ & $111 \pm 10$ & $351 \pm 27$ & $369 \pm 17$ & $100 \pm 11$ & $91 \pm 11$ & $356 \pm 24$ & $340 \pm 16$ \\
\hline E2 & $94 \pm 12$ & $91 \pm 13$ & $369 \pm 24$ & $343 \pm 16$ & $89 \pm 13$ & $95 \pm 9$ & $341 \pm 17$ & $336 \pm 19$ \\
\hline P4 & $78 \pm 10^{*}$ & $119 \pm 9$ & $321 \pm 17$ & $339 \pm 22$ & $78 \pm 8^{*}$ & $106 \pm 8$ & $319 \pm 22$ & $369 \pm 23$ \\
\hline LNG & $54 \pm 11^{*}$ & $89 \pm 12$ & $259 \pm 19^{*}$ & $321 \pm 19$ & $61 \pm 9^{*}$ & $109 \pm 11$ & $263 \pm 12^{*}$ & $335 \pm 17$ \\
\hline MPA & $72 \pm 13^{*}$ & $115 \pm 7$ & $261 \pm 24^{*}$ & $351 \pm 28$ & $66 \pm 12^{*}$ & $92 \pm 8$ & $245 \pm 11^{*}$ & $361 \pm 22$ \\
\hline NES & $81 \pm 11$ & $91 \pm 9$ & $249 \pm 20^{*}$ & $298 \pm 23^{*}$ & $75 \pm 8^{*}$ & $111 \pm 12$ & $266 \pm 18^{*}$ & $350 \pm 18$ \\
\hline NET & $49 \pm 8^{*}$ & $106 \pm 11$ & $237 \pm 16^{*}$ & $326 \pm 20$ & $55 \pm 10^{*}$ & $106 \pm 9$ & $220 \pm 25^{*}$ & $348 \pm 20$ \\
\hline NETA & $67 \pm 9^{*}$ & $90 \pm 9$ & $286 \pm 19 *$ & $378 \pm 14$ & $72 \pm 13^{*}$ & $113 \pm 11$ & $301 \pm 17^{*}$ & $356 \pm 25$ \\
\hline NEN & $75 \pm 8^{*}$ & $113 \pm 12$ & $336 \pm 26$ & $361 \pm 15$ & $69 \pm 14^{*}$ & $78 \pm 9^{*}$ & $321 \pm 25$ & $336 \pm 21$ \\
\hline NGM & $85 \pm 12$ & $90 \pm 8$ & $279 \pm 22^{*}$ & $306 \pm 22^{*}$ & $78 \pm 9^{*}$ & $135 \pm 11^{*}$ & $291 \pm 23^{*}$ & $343 \pm 24$ \\
\hline OHPC & $59 \pm 10$ & $109 \pm 11$ & $268 \pm 19^{*}$ & $322 \pm 21$ & $63 \pm 11^{*}$ & $106 \pm 12^{*}$ & $287 \pm 19^{*}$ & $326 \pm 22$ \\
\hline
\end{tabular}

$n=8$, results are expressed as mean \pm SEM

Note: E2, 17ß-estradiol; P4, progesterone; LNG, levonorgestrel; MPA, medroxyprogesterone acetate; NES, nestorone; NET, norethindrone; NETA, norethindrone acetate; NEN, norethynodrel; NGM, norgestimate; OHPC, hydroxyprogesterone caproate; RSV, resveratrol.

${ }^{*} P<0.05$, vs vehicle group in the same column 
(right panel of first row), prenatal exposure of P4 and all the eight different kinds of clinically relevant progestins significantly decreased ER $\beta$ expression and social interaction time (except the NEN), while prenatal resveratrol treatment (oral administration of $20 \mathrm{mg} / \mathrm{kg}$ RSV for 21 days) almost completely reversed prenatal progestin exposure-induced suppression effect on ER $\beta$ expression (partly for NEN) and social interaction time. Our results indicate that prenatal resveratrol treatment prevents prenatal progestin exposure-induced ER $\beta$ suppression and autism-like behavior.

\section{Postnatal resveratrol treatment reverses prenatal} norethindrone exposure-induced suppression of ER $\beta$ and its target genes in the amygdala

In Table 1, the prenatal exposure of norethindrone (NET) in pregnant dams showed the most dramatic suppression effect on ER $\beta$ expression and social interaction time in offspring compared to other progestins. The NET was chosen for the prenatal progestin exposure in the later experiments to investigate the detailed mechanism and effect of resveratrol on autism-like behavior. The animal was treated as shown in Fig. 1b. We first measured the gene expression of ER $\beta$, SOD2, and ERR $\alpha$ in the hypothalamus and hippocampus (see Additional file 1: Figure S1). We found that prenatal NET exposure showed no effect on gene expression. Also, RSV treatment showed no effect on the expression of ER $\beta$ and SIRT1, while the expression of SOD2 and $E R R \alpha$ was significantly increased in both the hypothalamus and hippocampus by RSV treatment compared to the control (CTL) group. We then measured the mRNA expression of ER $\beta$ (see Fig. 2a), SOD2 (see Fig. 2b), and ERR $\alpha$ (see Fig. 2c) in the amygdala. We

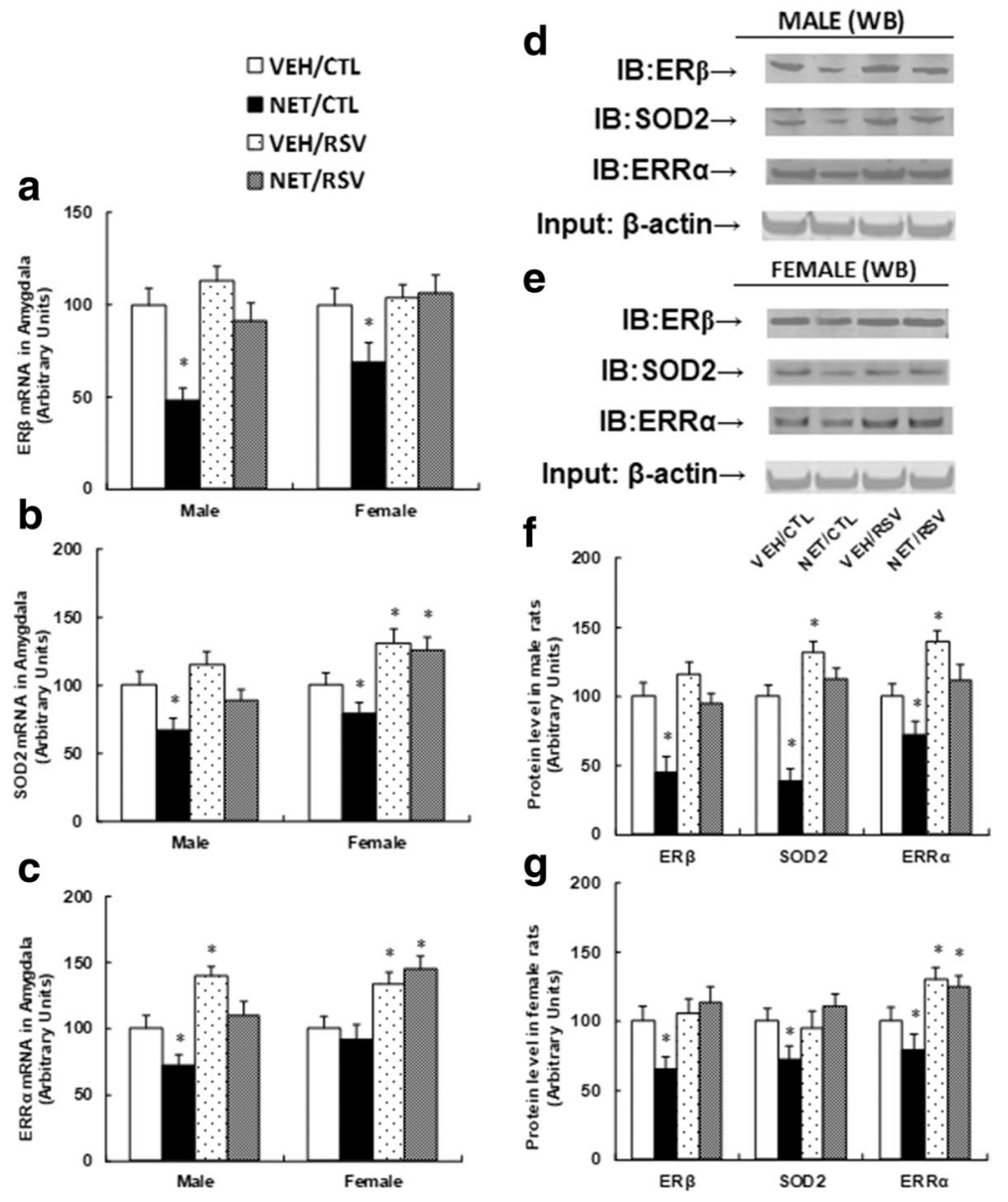

Fig. 2 Postnatal resveratrol treatment reverses prenatal norethindrone exposure-induced suppression of ERß and its target genes. Three-monthold pregnant dams were exposed to NET ( $20 \mu \mathrm{g}$ norethindrone) or VEH (vehicle, 5\% ethanol in organic sesame oil) by subcutaneous daily injection of $0.1 \mathrm{ml}$ for 21 days until pup delivery. Both male and female offspring were then treated with either control (CTL) or resveratrol (RSV) for 4 weeks starting from 5 weeks old. The offspring were sacrificed at 10 weeks of age to isolate the amygdala for further analysis. a-c mRNA levels in the amygdala for genes of ER $\beta \mathbf{a}, \operatorname{SOD} 2 \mathbf{b}$, and ERRa $\mathbf{c}, n=5$. $\mathbf{d}$ Representative pictures of protein levels in male offspring by western blotting. e Representative pictures of protein levels in female offspring by western blotting. $\mathbf{f}$ Protein expression quantitation for $\mathbf{d}, n=5$. $\mathbf{g}$ Protein expression quantitation for $\mathbf{e}, n=5 .{ }^{*}, P<0.05$, vs VEH/CTL group; $9, P<0.05$, vs NET/CTL group. Results are expressed as mean \pm SEM 
found that RSV treatment completely reversed prenatal NET exposure-induced suppression of ER $\beta$, SOD2, and ERR $\alpha$ in both male and female offspring. Furthermore, in female offspring, RSV significantly increased expression of SOD2 and ERR $\alpha$ in both the VEH and NET groups, while in male offspring there was much less gene activation (see Fig. 2b, c), indicating that female offspring seem more responsive to RSV treatment compared to male offspring. We also measured the protein levels in the amygdala (see Fig. $2 \mathrm{~d}-\mathrm{g}$ ). The results showed that RSV completely reversed the NET-mediated suppression effect on the expression of ER $\beta$, SOD2, and ERR $\alpha$. Furthermore, RSV increased ERR $\alpha$ expression in VEH treatment compared to the CTL group in male offspring (see Fig. 2d, f), and in female offspring, RSV significantly increased ERR $\alpha$ expression in both VEH and NET treatment compared to CTL group (see Fig. 2e, g). We also measured the SIRT1 mRNA expression (see Figure S2a) and SIRT1 activity (see Figure S2b), which showed no difference in any of the treatments, indicating that SIRT1 may not be involved in RSV-mediated effect (see detailed statistical information in Additional file 1: Data S1). Our results suggest that RSV reverses prenatal NET exposure-induced suppression of ER $\beta$ and its target genes, and female offspring seem more responsive than male offspring.
Postnatal resveratrol treatment diminishes prenatal norethindrone exposure-induced methylation of DNA and histone on the ER $\beta$ promoter

In Fig. 3a, b, the DNA methylation on the ER $\beta$ promoter was significantly increased by prenatal NET exposure, and RSV treatment completely diminished this effect compared to the CTL group. We then measured the histone methylation on the ER $\beta$ promoter by ChIP techniques. In male offspring (see Fig. 3c), prenatal NET exposure increased H3K9 di-methylation (H3K9me2) by 1.80 -fold and H3K27 tri-methylation (H3K27me3) by 2.13 -fold, while in female offspring (see Fig. 3d), it increased H3K9 di-methylation (H3K9me2) by 2.14-fold and H3K27 tri-methylation (H3K27me3) by 1.56 -fold, but had no effect on H3K9 tri-methylation (H3K9me3). RSV treatment completely diminished the effect on H3K9me2, but partly diminished the effect on H3K27me3 in male offspring compared to the CTL group, while in female offspring, RSV partly diminished the effect on H3K9 di-methylation, but completely diminished the effect on H3K27 tri-methylation (see detailed statistical information in Additional file 1: Data S2). Our results indicate that postnatal RSV administration diminishes prenatal levonorgestrel exposure-induced methylation of DNA and histone on the ER $\beta$ promoter in the amygdala.
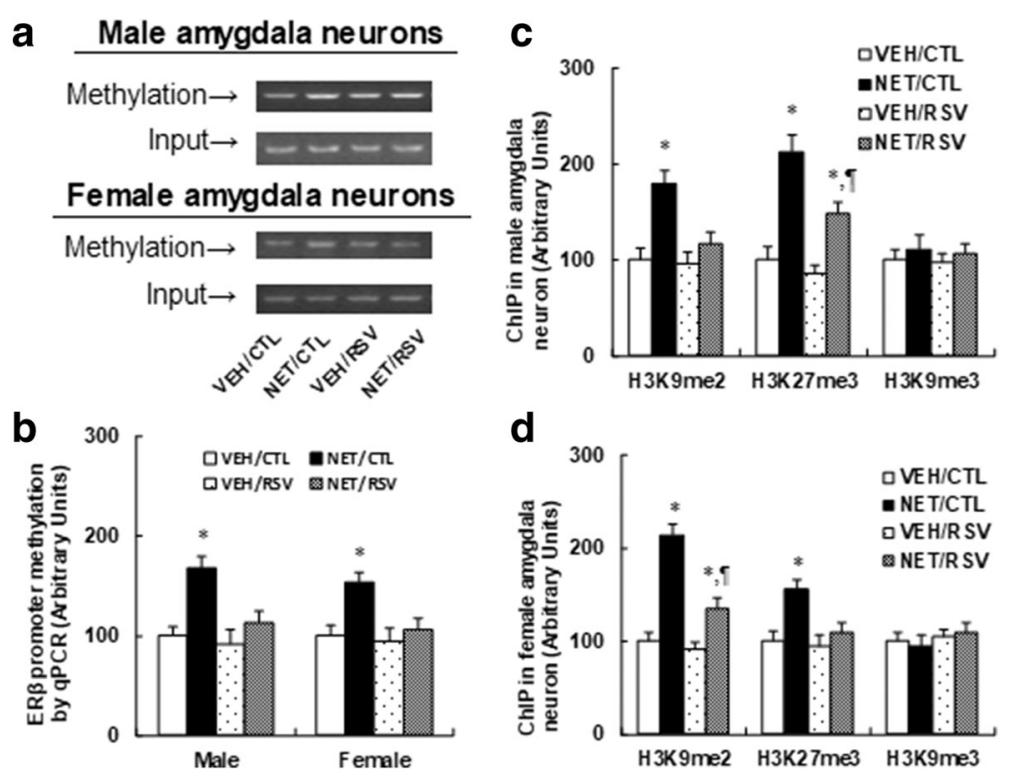

Fig. 3 Postnatal resveratrol treatment diminishes prenatal norethindrone exposure-induced methylation of DNA and histone on the ER $\beta$ promoter. The amygdala neurons were isolated from 10-week-old male/female offspring for in vitro cell culture analysis. a The representative bands for ERß methylation in amygdala neurons from both male (upper panel) and female (lower panel) offspring. $\mathbf{b}$ DNA methylation on ER $\beta$ by real-time PCRbased methylation-specific PCR (MSP) analysis in amygdala neurons, $n=5$. c ChIP analysis on the ER $\beta$ promoter in male amygdala neurons, $n=5$. $\mathbf{d}$ ChIP analysis on the ER $\beta$ promoter in female amygdala neurons, $n=5 .{ }^{*}, P<0.05$, vs VEH/CTL group; $\boldsymbol{9}, P<0.05$, vs NET/CTL group. Results are expressed as mean \pm SEM 
Postnatal resveratrol administration ameliorates prenatal norethindrone exposure-induced oxidative stress and dysfunction of mitochondria and lipid metabolism We evaluated the effect of RSV treatment on prenatal NET exposure-induced ER $\beta$ suppression and the subsequent molecular consequences in the amygdala, including ROS generation, DNA damage, mitochondrial function and lipid metabolism. We found that prenatal NET exposure significantly increased superoxide anion $\left(\mathrm{O}_{2}{ }^{-}\right)$release by 2.27 -fold (in male) and 1.88-fold (in female) respectively (see Fig. 4a); it increased 3 -nitrotyrosine formation by 2.03 -fold (in male) and 1.54-fold (in female) respectively (see Fig. 4b); it increased 8 -OHdG formation by 2.65 -fold (in male) and 2.27 -fold (in female) respectively (see Fig. 4c); it increased $\gamma \mathrm{H} 2 \mathrm{AX}$ formation by 1.94-fold (in male) and 1.48 -fold (in female) respectively (see Fig. 4d, e); it decreased mitochondrial DNA copies by $38 \%$ (in male) and $24 \%$ (in female) respectively (see Fig. 4f); it decreased intracellular ATP level by $45 \%$ (in male) and 25\% (in female) respectively (see Fig. 4g). Furthermore, it decreased in vivo fatty acid oxidation by $47 \%$ (in male) and $18 \%$ (in female) respectively (see Fig. 4h), and it decreased in vitro fatty acid uptake by $42 \%$ (in male) and $26 \%$ (in female) respectively (see Fig. 4i). RSV treatment partly reversed this effect in male offspring, while in female offspring, RSV completely diminished this effect. Furthermore, in VEH group, RSV treatment significantly increased mitochondrial function (see Fig. 4f, g) and in vivo fatty acid oxidation metabolism (see Fig. 4h) in both male and female offspring. On the other hand, RSV treatment increased in vitro fatty acid uptake (see Fig. 4i) in female offspring but not in male offspring from VEH group (see detailed statistical information in Additional file 1: Data S3). Our results indicate that RSV ameliorates prenatal NET exposure-induced oxidative stress and dysfunction of mitochondria and lipid metabolism, and that female
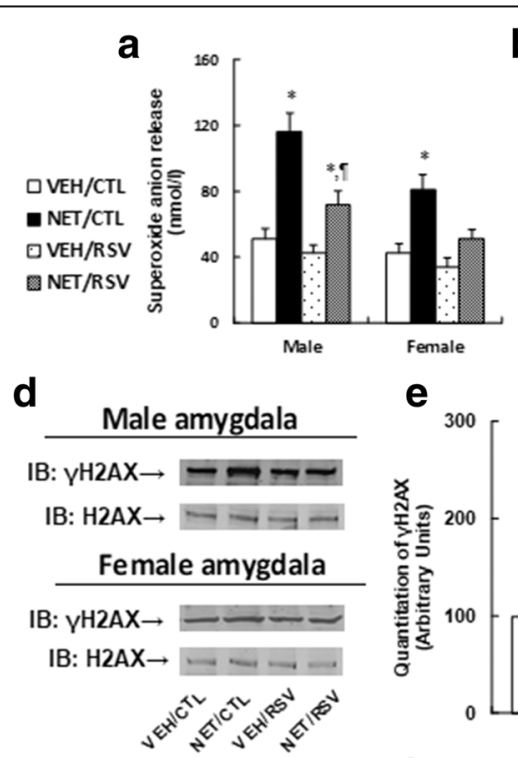

g

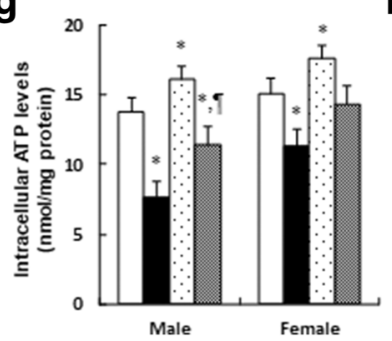

e

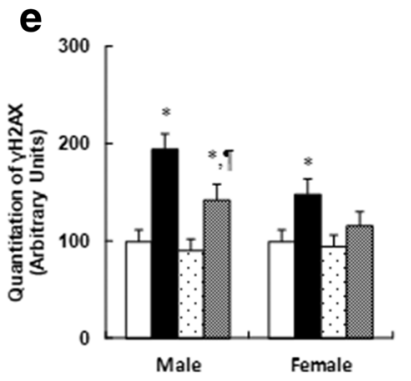

h

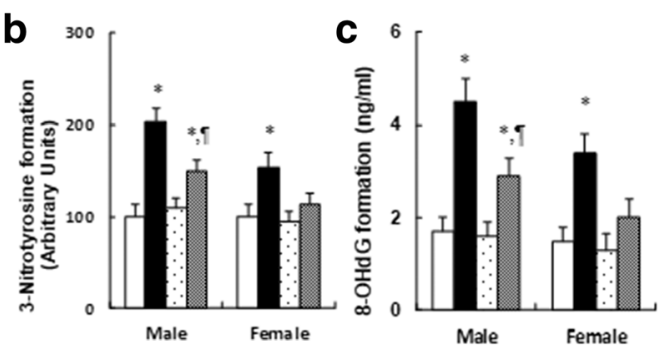

$f$
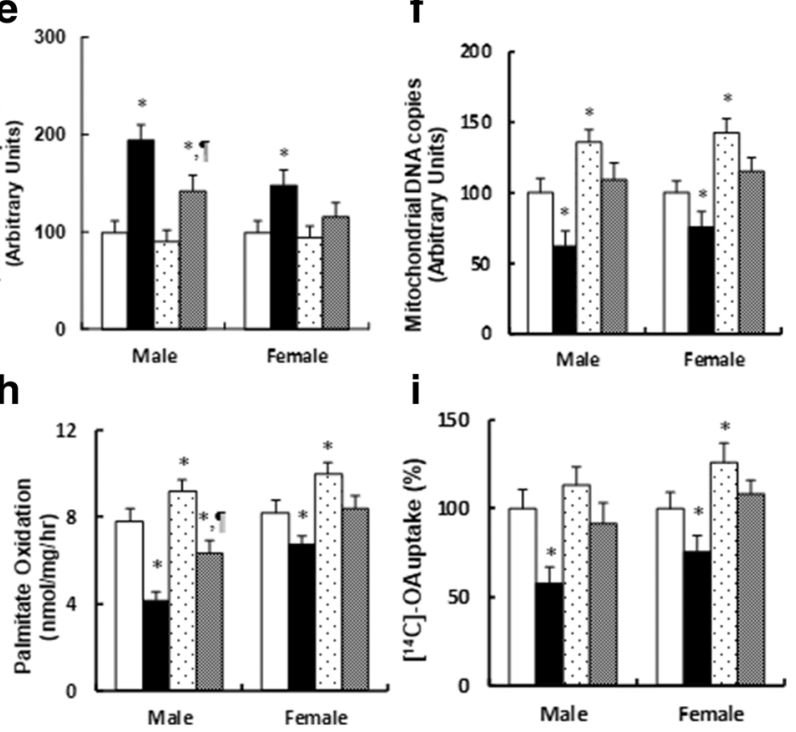

Fig. 4 Postnatal resveratrol treatment ameliorates prenatal norethindrone exposure-induced oxidative stress, dysfunction of mitochondria, and lipid metabolism. $\mathbf{a}-\mathbf{h}$ The amygdala tissues were isolated from 10-week-old male/female offspring for further analysis. a In vivo superoxide anion release, $n=5$. b Quantitation of 3-nitrotyrosine (3-NT) formation, $n=5$. c 8-OHdG formation, $n=5$. d Representative $\gamma H 2 A X$ western blotting band for both male (upper panel) and female (down panel) offspring. e Quantitation of $\gamma \mathrm{H} 2 \mathrm{AX}$ formation for $\mathbf{d}, n=5$. $\mathbf{f}$ Mitochondrial DNA copies, $n=$ 4. $\mathbf{g}$ Intracellular ATP levels, $n=5$. $\mathbf{h}$ The in vivo palmitate oxidation rate, $n=5$. $\mathbf{i}$ The amygdala neurons were isolated from 10 -week-old male/ female offspring for in vitro ${ }^{14} \mathrm{C}-\mathrm{OA}$ fatty acid uptake, $n=5 .{ }^{*}, P<0.05$, vs VEH/CTL group; $\boldsymbol{\uparrow}, P<0.05$, vs NET/CTL group. Results are expressed as mean \pm SEM 
offspring were less responsive to NET exposure than male offspring.

\section{Postnatal resveratrol treatment ameliorates prenatal} norethindrone exposure-induced autism-like behavior We measured the effect of RSV on prenatal NET exposure-induced autism-like behavior. In male offspring, prenatal NET exposure decreased buried marbles by $52 \%$ (see Fig. $5 \mathrm{a}$ ), while there was no difference in female offspring. We then evaluated the social interaction time. In male offspring, the NET treatment decreased by $32 \%$ in sniffing, $48 \%$ in mounting, no difference in grooming partner, and $33 \%$ in total social interaction (see Fig. 5b), while RSV treatment completely diminished this effect. In female offspring, the NET treatment decreased by $20 \%$ in sniffing, no difference in mounting or grooming partner, and $22 \%$ in total social interaction (see Fig. 5c). Furthermore, the RSV treatment completely diminished this effect in both male and female offspring (see detailed statistical information in Additional file 1: Data S4). Our results indicate that RSV completely reverses prenatal NET exposure-induced autism-like behavior and that male offspring seem more sensitive to NET-induced effect compared to female offspring.
Postnatal resveratrol treatment ameliorates prenatal norethindrone exposure-induced autism-like behavior through ER $\beta$ activation

Prenatal NET exposure treated male offspring received lentivirus infusion of shER $\beta$ shown in Fig. 1b. We first measured the gene expression of ER $\beta$, SOD2, and ERR $\alpha$. The results showed that prenatal NET exposure significantly decreased mRNA levels (see Fig. 6a) and protein levels (see Fig. 6b, c) of those genes. We then measured prenatal NET exposure-mediated molecular consequences in the amygdala. The results showed that postnatal resveratrol treatment ameliorates prenatal NET exposure-induced oxidative stress (see Additional file 1: Figure S3a, b), DNA damage (see Additional file 1: Figure S3c, e), dysfunction of mitochondria (see Additional file 1: Figure S3f, g), and lipid metabolism (see Additional file 1: Figure S3 h, i) through ER $\beta$ activation. RSV treatment completely reversed this suppression effect, while ER $\beta$ knockdown (shER $\beta$ ) significantly diminished the effect of RSV (see Additional file 1: Figure S3). Next, we investigated the potential effect of RSV treatment and ER $\beta$ expression on prenatal NET exposure-induced autism-like behavior in male offspring. We found that prenatal NET exposure (NET/EMP/CTL) decreased buried marbles by $32 \%$ (see Fig. 6d) compared to the control group. RSV treatment completely reversed prenatal NET exposure-induced
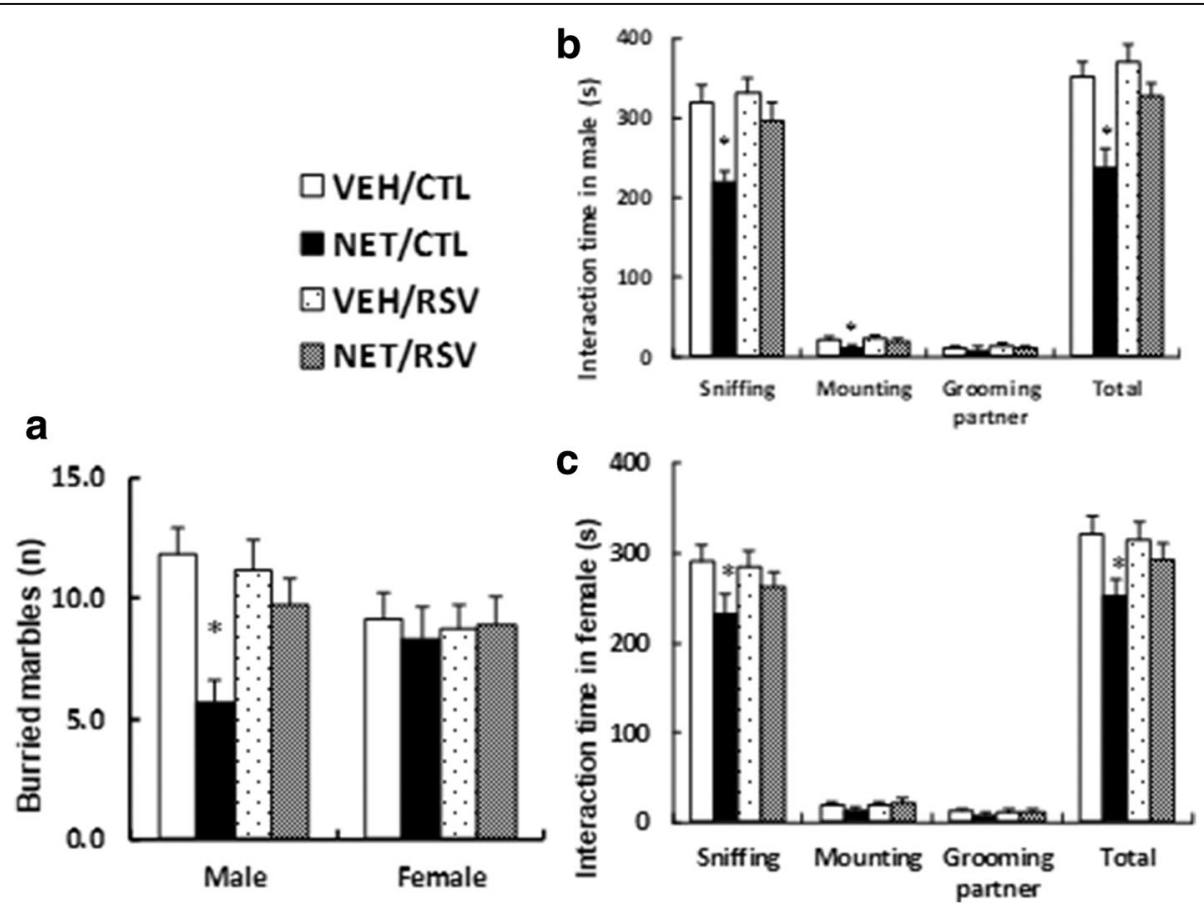

Fig. 5 Postnatal resveratrol treatment ameliorates prenatal norethindrone exposure-induced autism-like behavior. Three-month-old pregnant dams were exposed to NET (20 $\mathrm{\mu g}$ levonorgestrel) or VEH (vehicle, $5 \%$ ethanol in organic sesame oil) by subcutaneous daily injection of $0.1 \mathrm{ml}$ for 21 days until pup delivery. Both male and female offspring were then treated by either control (CTL) or resveratrol (RSV) for 4 weeks starting from 5 weeks old. Both male and female offspring were used for autism-like behavior tests at 10 weeks old. a Buried marble tests, $n=9$. b, $\mathbf{c}$ Social interaction time in both male (b) and female (c) offspring, $n=9$. ${ }^{*}, P<0.05$, vs VEH/CTL group; $\boldsymbol{\uparrow}, P<0.05$, vs NET/CTL group. Results are expressed as mean \pm SEM 


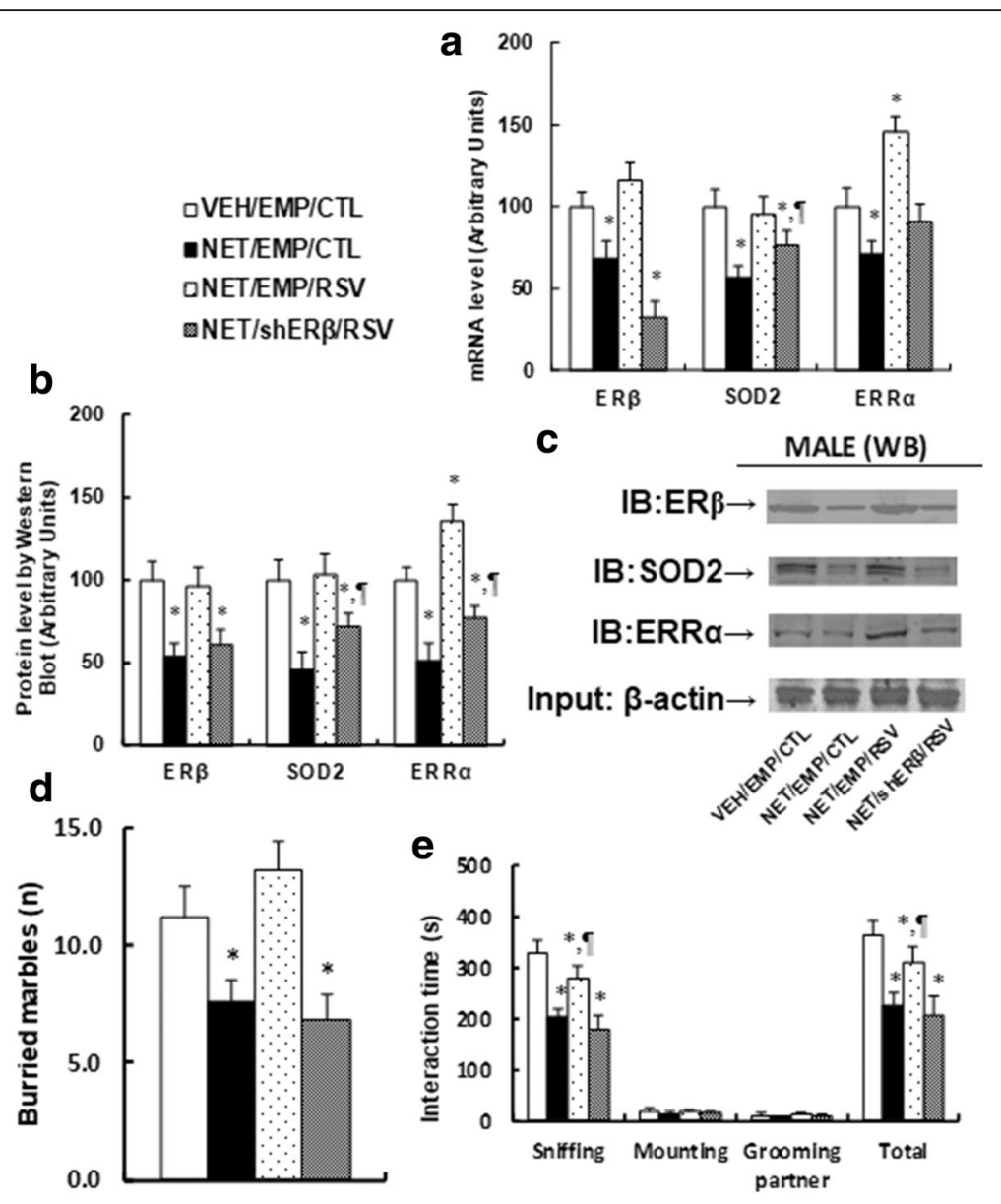

Fig. 6 Postnatal resveratrol treatment ameliorates prenatal norethindrone exposure-induced autism-like behavior through ER $\beta$ activation. The 8week-old male offspring from VEH or NET group received either empty (EMP) or ER $\beta$ knockdown (shER $\beta$ ) lentivirus infusion and were treated by either control (CTL) or resveratrol (RSV) for 4 weeks, and the offspring were sacrificed at 13 weeks of age for further analysis. a-c The amygdala tissues were isolated from 13-week-old treated male offspring for gene expression analysis. a The mRNA levels for gene expression, $n=4$. $\mathbf{b}$ The quantitation of protein levels, $n=5$. c Representative bands for western blots. d Buried marble tests, $n=9$. e Interaction time, $n=9$. ${ }^{*}, P<0.05$, vs VEH/EMP/CTL group; $9, P<0.05$, vs NET/EMP/CTL group; \#, $P<0.05$, vs NET/EMP/RSV group. Results are expressed as mean \pm SEM

autism-like behavior, while ER $\beta$ knockdown (shER $\beta)$ completely diminished the effect of RSV. We also measured the social interaction time (see Fig. 6e). The results showed that prenatal NET exposure resulted in a $38 \%$ decrease in sniffing and a $37 \%$ decrease in total social interaction, while it showed no difference in mounting and grooming partner. RSV treatment partly diminished this effect, while ER $\beta$ knockdown (shER $\beta$ ) completely diminished the effect of RSV (see detailed statistical information in Additional file 1: Data S5). Our results indicate that RSV ameliorates prenatal norethindrone exposure-induced autism-like behavior in offspring through ER $\beta$ activation.

\section{Prenatal resveratrol treatment prevents prenatal} norethindrone exposure-induced autism-like behavior Three-month-old pregnant dams were exposed to either NET (20 $\mu$ g norethindrone) or VEH (vehicle) for 21 days during the whole pregnancy, and they also received either control (PreCTL) or resveratrol (PreRSV) prenatal treatment by oral administration. Both male and female offspring at 10 weeks of age were used for biomedical analysis and autism-like behavior testing. We first measured the ER $\beta$ gene expression (see Fig. 7a) and found that prenatal RSV treatment completely reversed prenatal NET exposure-induced ER $\beta$ suppression. We also measured the epigenetic changes with histone methylation on the ER $\beta$ promoter in both male (see Additional file 1: Figure S4a) and female offspring (see Additional file 1: Figure S4b). We found that prenatal RSV treatment completely normalized prenatal NET exposure-induced histone methylation, including H3K9me2 and H3K27me3. We also measured the oxidative stress, including superoxide anion (see Additional file 1: Figure S4c) and 8-OHdG formation (see Additional file 1: Figure S4d); mitochondria functions, including mitochondrial DNA copies (see Additional file 1: Figure S4e) and 


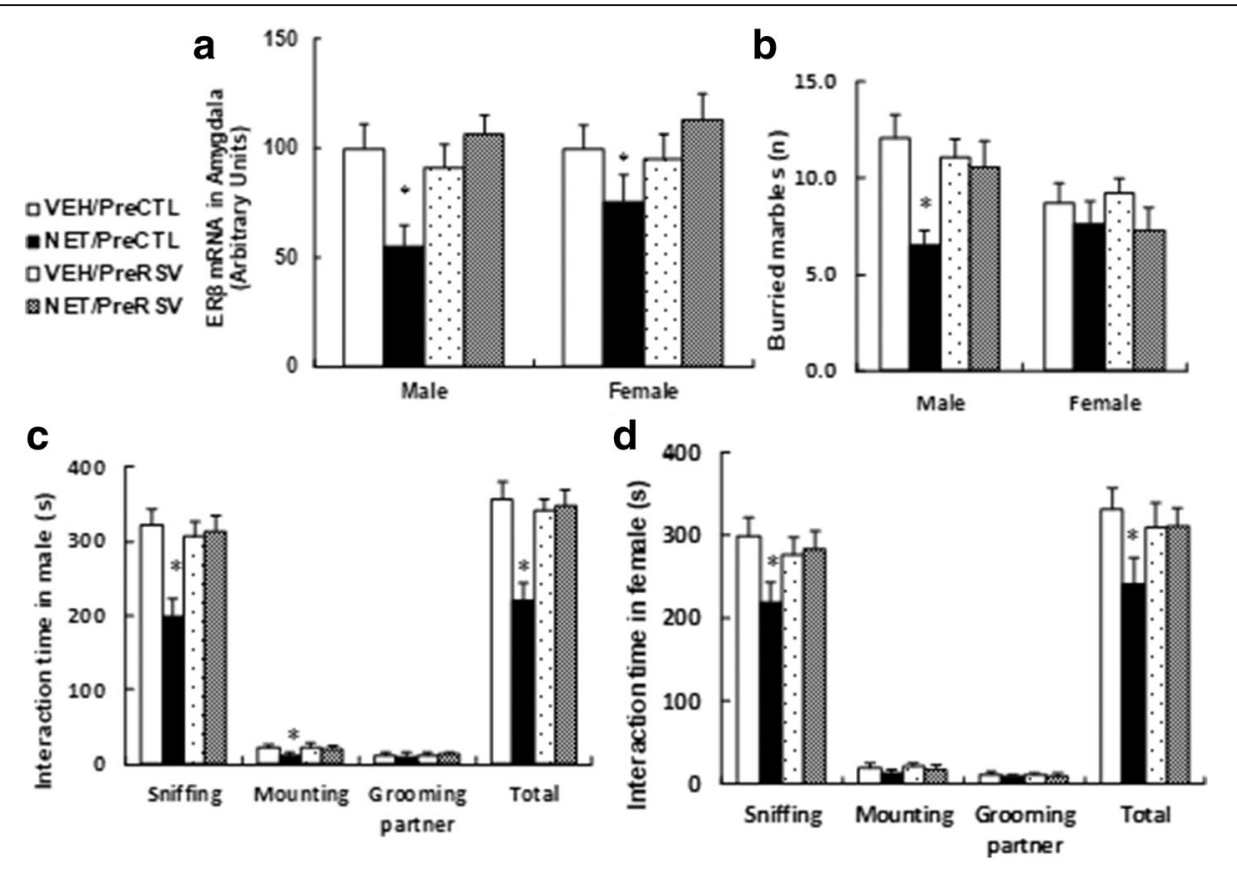

Fig. 7 Prenatal resveratrol treatment prevents prenatal norethindrone exposure-induced autism-like behavior. Three-month old pregnant dams were exposed to NET (20 $\mathrm{gg}$ norethindrone) or VEH (vehicle only) by subcutaneous daily injection of $0.1 \mathrm{ml}$ for 21 days until pup delivery. In addition, all the dams received either control (PreCTL) or resveratrol (PreRSV) treatment by oral administration at the same time. At 10 weeks of age, both male and female offspring were used for gene expression analysis and autism-like behavior testing. $\mathbf{a}$ The ER $\beta$ mRNA level, $n=4$. $\mathbf{b}$ Buried marble tests, $n=9$. $\mathbf{c}$, d Interaction time for both male (c) and female (d) offspring, $n=9 .{ }^{*}, P<0.05$, vs VEH/CTL group. Results are expressed as mean \pm SEM

intracellular ATP level (see Additional file 1: Figure S4f); as well as lipid metabolism, including palmitate oxidation (see Additional file 1: Figure S4 g) and fatty acid uptake (see Additional file 1: Figure S4 h). It showed that prenatal RSV treatment completely (in female offspring) or partly (in male offspring) reversed NET-induced effect compared to control group. Finally, we measured autism-like behavior, including buried marble testing (see Fig. 7b) and social interaction time testing for both male (see Fig. 7c) and female offspring (see Fig. 7d). We found that prenatal RSV treatment completely reversed prenatal NET exposure-induced autism-like behavior in both male and female offspring (see detailed statistical information in Additional file 1: Data S6). Our results indicate that prenatal RSV treatment prevents prenatal NET exposure-induced autism-like behavior.

\section{Discussion}

In this study, we show that prenatal progestin exposure decreases ER $\beta$ expression in the brain and induces autism-like behavior in offspring. Oral administration of RSV reverses prenatal progestin exposure-induced ER $\beta$ suppression by demethylation of DNA and histone on the ER $\beta$ promoter in the amygdala in offspring. RSV-mediated ER $\beta$ activation then upregulates the expression of SOD2 and ERR $\alpha$ and minimizes the oxidative stress and dysfunction of mitochondria [6] and lipid metabolism, subsequently ameliorating prenatal progestin exposure-induced autism-like behavior. In addition, prenatal resveratrol treatment prevents prenatal progestin exposure-induced autism-like behavior in offspring.

\section{Association of progestin and ASD development}

Natural progesterone or synthetic progestins, such as hydroxyprogesterone caproate (OHPC), have been used to reduce the incidence of preterm birth [44], where there is a signal for embryo-fetal toxicity associated with $\mathrm{OHPC}$ in the two largest clinical trials [45]. Progestin is the major component in hormone replacement therapy (HRT) and combined oral contraceptive (COC), and taking oral contraceptives when pregnancy begins is a strong risk factor for ASD development [8]. Also, progestin concentrations found in water can suppress ER $\beta$ expression and affect brain functions [21, 46]. Our current data show that prenatal progestin exposure suppresses ER $\beta$ expression in the amygdala [47] and subsequently contributes to ASD development [9]. This consideration may potentially apply to humans, as prenatal progestin exposure may be associated with ASD development via directly or indirectly taking progestin compounds, which includes 
contraceptive pills, progesterone/progestin pills to prevent threatened abortion, and COC-contaminated drinking water and seafood during pregnancy [21].

\section{Resveratrol-mediated demethylation of DNA and histone on the ER $\beta$ promoter}

It has been reported that RSV inhibits DNA methyltransferases (DNMTs) [48] and subsequently decreases DNA methylation [49] and histone methylation [50, 51]. We show that RSV in vivo treatment significantly decreases both DNA methylation and histone methylation on the ER $\beta$ promoter, and subsequently increases ER $\beta$ expression. This is the first time we report the potential neuroprotective mechanism of RSV through RSV-mediated demethylation with subsequent gene activation. Furthermore, we show that RSV treatment can only demethylate prenatal NET exposure-mediated hypermethylation on both DNA and histone, while it has little effect on basal methylation in the prenatal VEH exposure group. This suggests that RSV-mediated demethylation is not only due to RSV-mediated DNMT inhibition, but rather that some other indirect factors may also be involved [52].

\section{Resveratrol-mediated ER $\beta$ activation}

We have previously reported that ER $\beta$ expression is regulated by SIRT1 through complexes of SIRT1-PPAR $\gamma /$ RXR-p300 on the ER $\beta$ promoter [14], and RSV has been reported to be able to activate SIRT1 either directly [53] or indirectly through AMPK activation [54]. We suppose that resveratrol treatment should be able to activate SIRT1 and subsequently upregulate ER $\beta$ expression, while our results show that RSV treatment significantly increases ER $\beta$ expression, but neither SIRT1 expression nor activity changes in the amygdala, suggesting that a SIRT1-independent ER $\beta$ activating mechanism is required for RSV-mediated ER $\beta$ activation. Our further investigation shows that RSV treatment in vivo significantly alters DNA methylation and epigenetic changes with demethylation on the ER $\beta$ promoter in the amygdala, which subsequently activates ER $\beta$ expression with ameliorated autism-like behavior. This is the first time we report the potential mechanism for RSV-mediated gene activation through demethylation of either DNA or histone in the nervous system, which sheds a light on rescuing ASD symptoms through resveratrol treatment.

\section{Resveratrol-mediated activation of SOD2 and ERRa}

Our results show that resveratrol (RSV) treatment reverses prenatal NET exposure-induced methylation of DNA and histone on the ER $\beta$ promoter and subsequently reverses prenatal NET exposure-induced ER $\beta$ suppression, but it does not change the basal DNA and histone methylation level and subsequent basal ER $\beta$ expression. On the other hand, the basal expression level of SOD2 and ERR $\alpha$ increases significantly in response to RSV treatment in not only the amygdala, but also in the hypothalamus and hippocampus; this kind of gene activation is not regulated by ER $\beta$ as reported previously $[11,12]$ since the basal ER $\beta$ expression has no change in response to RSV treatment. Also, the in vitro cell culture experiments show that RSV treatment significantly increases the expression of SOD2 and ERR $\alpha$, and female offspring seem more responsive to RSV treatment compared to male offspring. This can be explained because the female offspring have higher basal ER $\beta$ expression compared to male offspring, or because RSV can directly activate SOD2 and ERR $\alpha$ expression through another pathway, such as PGC1 $\alpha$ [53]. Furthermore, in female rats, RSV increased expression of both SOD2 and ERR $\alpha$, even in rats that were not exposed to NET, suggesting a more general effect. Our results indicate that another factor other than ER $\beta$ may also be involved in regulating the gene activation of SOD2 and ERR $\alpha$. This can be explained by RSV-mediated PGC- $1 \alpha$ activation, as it has been reported that RSV activates PGC- $1 \alpha$ either by SIRT1 [53] or AMPK (54)-mediated indirect activation or by direct deacetylation of PGC-1 $\alpha$ [55], and the activated PGC- $1 \alpha$ then upregulates the expression of ERR $\alpha$ $[56,57]$ and SOD2 [58].

\section{Limitations}

This study has several limitations. In animal behavioral tests, the marble burying test and the social interaction time were used for the evaluation of autism-like behavior, while these tests do not really reflect adequate tests of this syndrome. The marble burying test has been used to describe anxiety and repetitive behavior, but not clearly presented as a test for autism. A more common test for autism should be the social preference test and the ultrasonic vocalization test. In addition, during the animal treatment, prenatal exposure of either progestin or resveratrol was used throughout the whole pregnancy period (21 days), while this rarely happens in the human being. Usually, the first trimester during the pregnancy is considered as the most sensitive period for the prenatal exposure of risk factors; in this case, prenatal exposure of progestin or resveratrol during the first 7 days of pregnancy in dams may be more reasonable for this treatment. On the other hand, we were using higher doses of resveratrol and progestin for the treatment of pregnant dams in this study in order to achieve a significant effect in animals to mimic the long-term exposure of lower doses in humans, and this may be a potential limitation for human application. 


\section{Conclusions}

Our results indicate that prenatal progestin exposure is a strong risk factor for autism-like behavior. Many potential clinical progestin applications, including oral contraceptive pills, preterm birth drugs, and progestin-contaminated drinking water or seafood, may be risk factors for potential ASD development. In addition, resveratrol may be a good candidate for rescuing and preventing ASD symptoms in humans through ER $\beta$ upregulation.

\section{Additional file}

Additional file 1: Table S1. Sequences of primers for the real time quantitative PCR ( $q P C R$ ). Figure S1. Postnatal resveratrol treatment increases expression of SOD2 and ERRa, while it has no effect on the expression of ER $\beta$ and SIRT1 in the hypothalamus and hippocampus of prenatal norethindrone exposed offspring. Figure S2. Both resveratrol and norethindrone treatment do not change the expression and activity of SIRT1 in the amygdala. Figure S3. Postnatal resveratrol treatment ameliorates prenatal norethindrone exposure-induced oxidative stress, dysfunction of mitochondria and lipid metabolism through ERß activation. Figure S4. Prenatal resveratrol treatment prevents prenatal norethindrone exposure-induced epigenetic changes, oxidative stress, and the dysfunction of mitochondria and lipid metabolism. Data S1. Statistical details for Fig. 2. Data S2. Statistical details for Fig. 3. Data S3. Statistical details for Fig. 4. Data S4. Statistical details for Fig. 5. Data S5. Statistical details for Fig. 6. Data S6. Statistical details for Fig. 7. (DOCX 402 kb)

\section{Abbreviations}

ASD: Autism spectrum disorder; ChIP: Chromatin immunoprecipitation; COC: Combined oral contraceptive; E2: 17ß-estradiol; EMP: Empty control; ERRa: Estrogen-related receptor a; ERß: Estrogen receptor $\beta$; HRT: Hormone replacement therapy; LNG: Levonorgestrel; MBT: Marbles burying test; MPA: Medroxyprogesterone acetate; NEN: Norethynodrel; NES: Nestorone; NET: Norethindrone; NETA: Norethindrone acetate; NGM: Norgestimate; OHPC: Hydroxyprogesterone caproate; P4: Progesterone; RSV: Resveratrol; SI: Social interaction; SOD2: Mitochondrial superoxide dismutase; VEH: Vehicle control

\section{Funding}

This study was financially supported by The National Natural Science Foundation of China, Project \#: 81772097; Natural Science Foundation of Hubei Province of China, Project \#: 2016CFB473; and Bureau of Public Health of Hainan Province, Key Project \# 14A110065.

\section{Authors' contributions}

PY wrote the paper. PY, WX, and HC designed and interpreted the experiments. $A Y, X G, Z C$, and $X H$ performed the rat surgery and social behavior testing. $X W, Y W$, and $X G$ performed the virus preparation and gene analysis. $Z \mathrm{~L}, \mathrm{YJ}$, and $\mathrm{MX}$ performed the amygdala isolation and analysis. $\mathrm{WX}$, $X G$, and $L L$ performed the remaining experiments. All authors read, edited, and approved the final manuscript.

\section{Ethics approval}

The animal protocol conformed to the US NIH guidelines (Guide for the Care and Use of Laboratory Animals, No. 85-23, revised 1996) and was reviewed and approved by the Institutional Animal Care and Use Committee from Wuhan University.

\section{Consent for publication}

Not applicable.

\section{Competing interests}

Authors including Drs Xiaohu Ge, Xiaoyan Wang, Yifei Wang, and Haijia Chen, were employed by the company Guangzhou SALIAI Stem Cell Science and Technology Co. LTD. All other authors declare that they have no competing interests.

\section{Publisher's Note}

Springer Nature remains neutral with regard to jurisdictional claims in published maps and institutional affiliations.

Received: 5 February 2018 Accepted: 19 July 2018

Published online: 02 August 2018

\section{References}

1. Abrahams BS, Geschwind DH. Advances in autism genetics: on the threshold of a new neurobiology. Nat Rev Genet. 2008;9(5):341-55. 2. Volkmar FR, Pauls D. Autism. Lancet. 2003:362(9390):1133-41.

3. Bralten J, van Hulzen KJ, Martens MB, Galesloot TE, Arias Vasquez A, Kiemeney LA, Buitelaar JK, Muntjewerff JW, Franke B, Poelmans G. Autism spectrum disorders and autistic traits share genetics and biology. Mol Psychiatry. 2018;23(5):1205-12.

4. Schaafsma SM, Pfaff DW. Etiologies underlying sex differences in autism spectrum disorders. Front Neuroendocrinol. 2014;35(3):255-71.

5. Modabbernia A, Velthorst E, Reichenberg A. Environmental risk factors for autism: an evidence-based review of systematic reviews and meta-analyses. Mol Autism. 2017:8:13.

6. Rossignol DA, Frye RE. A review of research trends in physiological abnormalities in autism spectrum disorders: immune dysregulation, inflammation, oxidative stress, mitochondrial dysfunction and environmental toxicant exposures. Mol Psychiatry. 2012;17(4):389-401.

7. Strifert K. An epigenetic basis for autism spectrum disorder risk and oral contraceptive use. Med Hypotheses. 2015:85(6):1006-11.

8. Whitaker-Azmitia PM, Lobel M, Moyer A. Low maternal progesterone may contribute to both obstetrical complications and autism. Med Hypotheses. 2014;82(3):313-8.

9. Zou Y, Lu Q, Zheng D, Chu Z, Liu Z, Chen H, Ruan Q, Ge X, Zhang Z Wang $X$, et al. Prenatal levonorgestrel exposure induces autism-like behavior in offspring through ERbeta suppression in the amygdala. Mol Autism. 2017:8:46.

10. Crider A, Thakkar R, Ahmed AO, Pillai A. Dysregulation of estrogen receptor beta (ERbeta), aromatase (CYP19A1), and ER co-activators in the middle frontal gyrus of autism spectrum disorder subjects. Mol Autism. 2014;5(1):46.

11. Liu Z, Gou Y, Zhang H, Zuo H, Zhang H, Liu Z, Yao D. Estradiol improves cardiovascular function through up-regulation of SOD2 on vascular wall. Redox Biol. 2014;3(0):88-99.

12. Li H, Liu Z, Gou Y, Yu H, Siminelakis S, Wang S, Kong D, Zhou Y, Liu Z, Ding $Y$, et al. Estradiol mediates vasculoprotection via ERRalpha-dependent regulation of lipid and ROS metabolism in the endothelium. J Mol Cell Cardiol. 2015;87:92-101.

13. Zhan Y, Liu Z, Li M, Ding T, Zhang L, Lu Q, Liu X, Zhang Z, Vlessidis A, Aw $T Y$, et al. ERbeta expression in the endothelium ameliorates ischemia/ reperfusion-mediated oxidative burst and vascular injury. Free Radic Bio Med. 2016;96:223-33.

14. Kong D, Zhan Y, Liu Z, Ding T, Li M, Yu H, Zhang L, Li H, Luo A, Zhang D, et al. SIRT1-mediated ERbeta suppression in the endothelium contributes to vascular aging. Aging Cell. 2016;15(6):1092-102.

15. Rossignol DA, Frye RE. Evidence linking oxidative stress, mitochondrial dysfunction, and inflammation in the brain of individuals with autism. Front Physiol. 2014;5:150.

16. Mamidala MP, Polinedi A, Kumar PT, Rajesh N, Vallamkonda OR, Udani V Singhal N, Rajesh V. Maternal hormonal interventions as a risk factor for autism spectrum disorder: an epidemiological assessment from India. J Biosci. 2013:38(5):887-92.

17. Baron-Cohen S, Auyeung B, Norgaard-Pedersen B, Hougaard DM, Abdallah MW, Melgaard L, Cohen AS, Chakrabarti B, Ruta L, Lombardo MV. Elevated fetal steroidogenic activity in autism. Mol Psychiatry. 2015;20(3):369-76.

18. Gillberg C, Fernell E, Kocovska E, Minnis H, Bourgeron T, Thompson L, Allely CS. The role of cholesterol metabolism and various steroid abnormalities in autism spectrum disorders: a hypothesis paper. Autism Res. 2017;10(6):1022-44.

19. Liu L, Zhao L, She H, Chen S, Wang JM, Wong C, McClure K, Sitruk-Ware R, Brinton RD. Clinically relevant progestins regulate neurogenic and neuroprotective responses in vitro and in vivo. Endocrinology. 2010;151(12): 5782-94.

20. Willing J, Wagner CK. Exposure to the synthetic progestin, 17alphahydroxyprogesterone caproate during development impairs cognitive flexibility in adulthood. Endocrinology. 2016;157(1):77-82. 
21. Petersen LH, Hala D, Carty D, Cantu M, Martinovic D, Huggett DB. Effects of progesterone and norethindrone on female fathead minnow (Pimephales promelas) steroidogenesis. Environ Toxicol Chem. 2015;34(2):379-90.

22. Aguirre C, Jayaraman A, Pike C, Baudry M. Progesterone inhibits estrogenmediated neuroprotection against excitotoxicity by down-regulating estrogen receptor-beta. J Neurochem. 2010;115(5):1277-87.

23. Jayaraman A, Pike CJ. Progesterone attenuates oestrogen neuroprotection via downregulation of oestrogen receptor expression in cultured neurones. J Neuroendocrinol. 2009;21(1):77-81.

24. Dasgupta B, Milbrandt J. Resveratrol stimulates AMP kinase activity in neurons. Proc Natl Acad Sci U S A. 2007;104(17):7217-22.

25. Baur JA, Sinclair DA. Therapeutic potential of resveratrol: the in vivo evidence. Nat Rev Drug Discov. 2006;5(6):493-506.

26. Han YS, Zheng WH, Bastianetto S, Chabot JG, Quirion R. Neuroprotective effects of resveratrol against beta-amyloid-induced neurotoxicity in rat hippocampal neurons: involvement of protein kinase C. Br J Pharmacol. 2004;141(6):997-1005

27. Valenzano DR, Terzibasi E, Genade T, Cattaneo A, Domenici L, Cellerino A. Resveratrol prolongs lifespan and retards the onset of age-related markers in a short-lived vertebrate. Curr Biol. 2006;16(3):296-300.

28. Parker JA, Arango M, Abderrahmane S, Lambert E, Tourette C, Catoire H, Neri C. Resveratrol rescues mutant polyglutamine cytotoxicity in nematode and mammalian neurons. Nat Genet. 2005:37(4):349-50.

29. Bambini-Junior V, Zanatta G, Della Flora Nunes G, Mueller de Melo G, Michels M, Fontes-Dutra M, Nogueira Freire V, Riesgo R, Gottfried C. Resveratrol prevents social deficits in animal model of autism induced by valproic acid. Neurosci Lett. 2014:583:176-81.

30. Bakheet SA, Alzahrani MZ, Nadeem A, Ansari MA, Zoheir KMA, Attia SM, AlAyadhi LY, Ahmad SF. Resveratrol treatment attenuates chemokine receptor expression in the BTBR T+tf/J mouse model of autism. Mol Cell Neurosci. 2016;77:1-10.

31. Hu M, Richard JE, Maliqueo M, Kokosar M, Fornes R, Benrick A, Jansson T, Ohlsson C, Wu X, Skibicka KP, et al. Maternal testosterone exposure increases anxiety-like behavior and impacts the limbic system in the offspring. Proc Natl Acad Sci U S A. 2015;112(46):14348-53.

32. Bahi A. Sustained lentiviral-mediated overexpression of microRNA124a in the dentate gyrus exacerbates anxiety- and autism-like behaviors associated with neonatal isolation in rats. Behav Brain Res. 2016:311:298-308.

33. Hippocampal BA. BDNF overexpression or microR124a silencing reduces anxiety- and autism-like behaviors in rats. Behav Brain Res. 2017:326:281-90.

34. Mufford JT, Paetkau MJ, Flood NJ, Regev-Shoshani G, Miller CC, Church JS. The development of a non-invasive behavioral model of thermal heat stress in laboratory mice (Mus musculus). J Neurosci Methods. 2016;268:189-95.

35. Hay CW, Shanley L, Davidson S, Cowie P, Lear M, McGuffin P, Riedel G, McEwan IJ, Mackenzie A. Functional effects of polymorphisms on glucocorticoid receptor modulation of human anxiogenic substance-P gene promoter activity in primary amygdala neurones. Psychoneuroendocrinology. 2014:47:43-55.

36. Ogino S, Kawasaki T, Brahmandam M, Cantor M, Kirkner GJ, Spiegelman D, Makrigiorgos GM, Weisenberger DJ, Laird PW, Loda M, et al. Precision and performance characteristics of bisulfite conversion and real-time $P C R$ (MethyLight) for quantitative DNA methylation analysis. J Mol Diagn. 2006; 8(2):209-17.

37. Eads CA, Danenberg KD, Kawakami K, Saltz LB, Blake C, Shibata D, Danenberg PV, Laird PW. MethyLight: a high-throughput assay to measure DNA methylation. Nucleic Acids Res. 2000;28(8):E32.

38. Nosho K, Irahara N, Shima K, Kure S, Kirkner GJ, Schernhammer ES, Hazra A, Hunter DJ, Quackenbush J, Spiegelman D, et al. Comprehensive biostatistical analysis of $\mathrm{CpG}$ island methylator phenotype in colorectal cancer using a large population-based sample. PLoS One. 2008;3(11):e3698.

39. Hou X, Xu S, Maitland-Toolan KA, Sato K, Jiang B, Ido Y, Lan F, Walsh K, Wierzbicki M, Verbeuren TJ, et al. SIRT1 regulates hepatocyte lipid metabolism through activating AMP-activated protein kinase. J Biol Chem. 2008;283(29):20015-26

40. Yao D, Shi W, Gou Y, Zhou X, Yee Aw T, Zhou Y, Liu Z. Fatty acid-mediated intracellular iron translocation: a synergistic mechanism of oxidative injury. Free Radic Biol Med. 2005;39(10):1385-98.

41. Hagberg CE, Falkevall A, Wang X, Larsson E, Huusko J, Nilsson I, van Meeteren LA, Samen E, Lu L, Vanwildemeersch M, et al. Vascular endothelial growth factor B controls endothelial fatty acid uptake. Nature. 2010; 464(7290):917-21.
42. Taib B, Bouyakdan K, Hryhorczuk C, Rodaros D, Fulton S, Alquier T. Glucose regulates hypothalamic long-chain fatty acid metabolism via AMP-activated kinase (AMPK) in neurons and astrocytes. J Biol Chem. 2013;288(52):37216-29.

43. Huynh FK, Green MF, Koves TR, Hirschey MD. Measurement of fatty acid oxidation rates in animal tissues and cell lines. Methods Enzymol. 2014;542: 391-405.

44. Sanchez-Ramos L, Kaunitz AM, Delke I. Progestational agents to prevent preterm birth: a meta-analysis of randomized controlled trials. Obstet Gynecol. 2005;105(2):273-9.

45. Christian MS, Brent RL, Calda P. Embryo-fetal toxicity signals for 17alphahydroxyprogesterone caproate in high-risk pregnancies: a review of the non-clinical literature for embryo-fetal toxicity with progestins. J Matern Fetal Neonatal Med. 2007;20(2):89-112.

46. Giatti S, Melcangi RC, Pesaresi M. The other side of progestins: effects in the brain. J Mol Endocrinol. 2016:57(2):R109-26.

47. van Wingen GA, van Broekhoven F, Verkes RJ, Petersson KM, Backstrom T, Buitelaar JK, Fernandez G. Progesterone selectively increases amygdala reactivity in women. Mol Psychiatry. 2008;13(3):325-33.

48. Hardy TM, Tollefsbol TO. Epigenetic diet: impact on the epigenome and cancer. Epigenomics. 2011;3(4):503-18.

49. Lou XD, Wang HD, Xia SJ, Skog S, Sun J. Effects of resveratrol on the expression and DNA methylation of cytokine genes in diabetic rat aortas. Arch Immunol Ther Exp. 2014;62(4):329-40.

50. Paluszczak J, Krajka-Kuzniak V, Baer-Dubowska W. The effect of dietary polyphenols on the epigenetic regulation of gene expression in MCF7 breast cancer cells. Toxicol Lett. 2010;192(2):119-25.

51. Han S, Uludag MO, Usanmaz SE, Ayaloglu-Butun F, Akcali KC, Demirel-Yilmaz E. Resveratrol affects histone 3 lysine 27 methylation of vessels and blood biomarkers in DOCA salt-induced hypertension. Mol Biol Rep. 2015;42(1):35-42.

52. Papoutsis AJ, Lamore SD, Wondrak GT, Selmin Ol, Romagnolo DF. Resveratrol prevents epigenetic silencing of BRCA-1 by the aromatic hydrocarbon receptor in human breast cancer cells. J Nutr. 2010;140(9):1607-14.

53. Lagouge M, Argmann C, Gerhart-Hines Z, Meziane H, Lerin C, Daussin F, Messadeq N, Milne J, Lambert P, Elliott $P$, et al. Resveratrol improves mitochondrial function and protects against metabolic disease by activating SIRT1 and PGC-1alpha. Cell. 2006;127(6):1109-22.

54. Canto C, Gerhart-Hines Z, Feige JN, Lagouge M, Noriega L, Milne JC, Elliott PJ, Puigserver P, Auwerx J. AMPK regulates energy expenditure by modulating NAD+ metabolism and SIRT1 activity. Nature. 2009:458(7241):1056-60.

55. Feige JN, Lagouge M, Canto C, Strehle A, Houten SM, Milne JC, Lambert PD, Mataki C, Elliott PJ, Auwerx J. Specific SIRT1 activation mimics low energy levels and protects against diet-induced metabolic disorders by enhancing fat oxidation. Cell Metab. 2008;8(5):347-58.

56. Lin J, Handschin C, Spiegelman BM. Metabolic control through the PGC-1 family of transcription coactivators. Cell Metab. 2005;1(6):361-70.

57. Schreiber SN, Emter R, Hock MB, Knutti D, Cardenas J, Podvinec M, Oakeley EJ, Kralli A. The estrogen-related receptor alpha (ERRalpha) functions in PPARgamma coactivator 1alpha (PGC-1alpha)-induced mitochondrial biogenesis. Proc Natl Acad Sci U S A. 2004;101(17):6472-7.

58. St-Pierre J, Drori S, Uldry M, Silvaggi JM, Rhee J, Jager S, Handschin C, Zheng K, Lin J, Yang W, et al. Suppression of reactive oxygen species and neurodegeneration by the PGC-1 transcriptional coactivators. Cell. 2006; 127(2):397-408.

Ready to submit your research? Choose BMC and benefit from:

- fast, convenient online submission

- thorough peer review by experienced researchers in your field

- rapid publication on acceptance

- support for research data, including large and complex data types

- gold Open Access which fosters wider collaboration and increased citations

- maximum visibility for your research: over $100 \mathrm{M}$ website views per year

At $\mathrm{BMC}$, research is always in progress.

Learn more biomedcentral.com/submission 